\title{
Monitoramento e modelagem da qualidade de água em uma bacia hidrográfica semiárida
}

\author{
Monitoring and modeling of water quality in a semiarid watershed
}

Berthyer Peixoto Lima', George Leite Mamede ${ }^{2}$, Iran Eduardo Lima Neto ${ }^{3}$

口-

\section{RESUMO}

O artigo teve como objetivo apresentar uma metodologia para caracterização da qualidade de água na Bacia Hidrográfica do Açude Acarape do Meio, no semiárido brasileiro. O mapeamento do uso do solo e o monitoramento de parâmetros de qualidade de água possibilitaram a identificação de fontes poluidoras e a construção do diagnóstico da bacia. A partir da modelagem da qualidade de água, $37 \mathrm{~km}$ do Rio Pacoti foram classificados como classe 4, exceto sua nascente, que ficou na classe 2. As principais fontes poluidoras para a degradação dos corpos hídricos foram as deficitárias Estações de Tratamento de Esgoto (ETEs), a falta de saneamento básico na zona rural, a pecuária e a atividade agrícola. O modelo QUAL-UFMG estimou a carga de entrada de fósforo no açude em 13,7 ton.ano-1 para uma concentração de 0,56 mg..-1 e vazão média em $1,48 \mathrm{~m}^{3} \mathrm{~s}^{-1}$. Os coeficientes calibrados $\mathrm{K}_{\mathrm{p}}, \mathrm{K}_{\mathrm{s}}, \mathrm{K}_{\mathrm{d}}, \mathrm{K}_{\mathrm{b},} \mathrm{K}_{\mathrm{spo}}, \mathrm{K}_{\mathrm{oi}}$ e $\mathrm{K}_{2}$ foram iguais a $0,45 d^{-1}, 0,29 d^{-1}, 0,68 d^{-1}, 0,65 d^{-1}, 0,1 d^{-1}, 0,01 d^{-1}$ e 5,4 $d^{-1}$, respectivamente. Avaliaram-se as intervenções políticas e infraestruturais na bacia em dois cenários: melhoria na eficiência de operação das ETEs e efetivação de políticas públicas, que reduziram consideravelmente a carga de fósforo.

Palavras-chave: classificação dos corpos d'água; modelo QUAL-UFMG; carga de fósforo em rio.

\begin{abstract}
This paper aimed at presenting a methodology for evaluating the water quality at the Acarape do Meio catchment, in the Brazilian semiarid. The land use mapping and monitoring of water quality parameters enabled the identification of main polluting sources and the construction of a catchment diagnosis. According to the water quality modelling, a stretch of $37 \mathrm{~km}$ along the Pacoti River was classified as class 4, except for those ones located at the catchment headwater, which was classified as class 2. The main polluting sources contributing to the water degradation were the inefficient Sewage Treatment Plants, the lack of basic sanitation in rural areas, livestock and agriculture activities. The QUAL-UFMG model estimated an affluent phosphorous load at the reservoir entrance of $13.7 \mathrm{ton}$. year-1 for the concentration of $0.56 \mathrm{mg.L}-1$ and mean water discharge of $1.48 \mathrm{~m}^{3}$.s-1. The $\mathrm{K}_{1}, \mathrm{~K}_{\mathrm{s}}, \mathrm{K}_{\mathrm{d}}, \mathrm{K}_{\mathrm{b}}, \mathrm{K}_{\mathrm{spo}}, \mathrm{K}_{\mathrm{oi}}$ and $\mathrm{K}_{2}$ coefficients were $0.45,0.29$, $0.68,0.65,0.1,0.01$ and $5.4 \mathrm{~d}-1$, respectively. The impacts of political and infrastructural measures over the catchment were evaluated taking into account two scenarios: improvement of efficiency at Sewage Treatment Plants and implementation of effective public policies, which reduced significantly the affluent phosphorous load into the reservoir.
\end{abstract}

Keywords: water bodies classification; model QUAL-UFMG; phosphorus load.

\section{INTRODUÇÃO}

O Estado do Ceará tem nas suas reservas hídricas superficiais sua principal fonte para atendimento aos múltiplos usos. Para o setor de abastecimento humano, as águas dos reservatórios monitorados pela Companhia de Gestão dos Recursos Hídricos (COGERH) fornecem $81 \%$ de toda essa demanda; já para os demais usos, como indústria e irrigação, esse valor supera os 90\% (CEARÁ, 2008).

O sistema hídrico que atende à demanda das bacias metropolitanas é formado pela interligação dos reservatórios Pacajus-Pacoti-RiachãoGavião, no entanto, tal sistema aporta água de outros reservatórios, entre eles o Açude Acarape do Meio (COGERH, 2010). Portanto, qualquer intervenção antrópica que ocorra nessa bacia de origem tem efeito direto no sistema hídrico que atende à Região Metropolitana de Fortaleza (RMF). A degradação da qualidade das águas nas bacias metropolitanas já é uma realidade preocupante, visto que os reservatórios estão eutrofizados ou hipereutrofizados (COGERH, 2016).

Ter conhecimento sobre as atividades que impactam a qualidade de água de uma bacia hidrográfica, e mais especificamente na região semiárida devido à intermitência de seus rios, é um mecanismo imprescindível para os gestores e tomadores de decisão em recursos hídricos. O Estado do Ceará ainda não efetuou qualquer enquadramento de corpos de água. Mapear o uso e a ocupação do solo para o diagnóstico de uma bacia, bem

${ }^{1}$ Gerente de Segurança de Barragens e Infraestrutura Hídrica da Companhia de Gestão dos Recursos Hídricos (COGERH). Doutorando na Universidade Federal do Ceará (UFC) - Fortaleza (CE), Brasil.

${ }^{2}$ Professor da Universidade da Integração Internacional da Lusofonia Afro-Brasileira (UNILAB) - Redenção (CE), Brasil.

${ }^{3}$ Professor da UFC - Fortaleza (CE), Brasil.

Endereço para correspondência: Berthyer Peixoto Lima - Rua Olegário Memória, 3.661 - Sapiranga - 60833-045 - Fortaleza (CE), Brasil - E-mail: berthyer.peixoto@cogerh.com.br Recebido em: 26/07/16 - Aceito em: 03/01/17 - Reg. ABES: 167115
} 
como avaliar a qualidade de suas águas e classificá-las são fases indispensáveis e obrigatórias para o processo de enquadramento de corpos de água em uma bacia hidrográfica, igualmente para a implementação de políticas públicas voltadas para o controle das poluições pontuais e difusas. Nessa perspectiva, a modelagem da qualidade de água se revela como uma estratégia para avaliar a condição atual do corpo hídrico, assim como antever cenários mais deletérios, o que proporcionará a construção de ações e programas para equacionar o problema e evitar o colapso hídrico.

É incontestável que o progresso da sociedade provoca o incremento da demanda por água, o que tem levado a alterações negativas na qualidade dos recursos hídricos (SANTOS et al., 2006). Maillard e Santos (2008), estudando a influência do uso e da ocupação do solo na qualidade de água para uma bacia no semiárido, concluíram que o uso do solo afetou diretamente o escoamento superficial, impactando nos valores de alguns parâmetros químicos, tais como turbidez, nitrogênio e coliformes totais.

Tomando por base o modelo QUAL2E, desenvolvido pela United States Environmental Protection Agency (Agência de Proteção Ambiental dos Estados Unidos - UESPA), o pesquisador Von Sperling (2007) desenvolveu o modelo denominado de QUAL-UFMG, saindo da condição da linguagem computacional para a plataforma em Excel. Isso proporcionou um modelo de melhor clareza em cada etapa da modelagem, ficando o processo mais simples. O modelo simula os parâmetros: oxigênio dissolvido (OD), demanda bioquímica de oxigênio (DBO), nitrogênio e suas frações, fósforo e suas frações e coliformes termotolerantes.

Paz e Barbosa (2010) inferiram que o modelo QUAL-UFMG se mostrou uma importante ferramenta para analisar os efeitos da poluição por fontes pontual e não pontual e para avaliação de cenários, objetivando o cumprimento da legislação pertinente. Teodoro et al. (2013) também trabalharam com esse modelo para gerar cenários para o Rio Taquari e enalteceram sua simplicidade e eficácia, corroborando o que Lindenschmidt (2006) afirmara no estudo de incertezas de modelos na modelagem da qualidade de rios quanto à complexidade dos arquétipos.

Amin et al. (2017) utilizaram o modelo Soil and Water Assessment Tool (SWAT) para estimar a carga de nutrientes e de sedimentos em uma bacia cárstica na Pensilvânia (EUA) e concluíram que o uso de modelos pode ser uma poderosa ferramenta para a gestão dos recursos hídricos.

Salla et al. (2013) utilizaram o modelo QUAL-UFMG para avaliar a capacidade de autodepuração do Rio Jordão, Minas Gerais, e concluíram que o referido modelo conseguiu simular as condições atuais e de cenários futuros. Costa e Teixeira (2010), aplicando o mesmo modelo para a Bacia Hidrográfica do Ribeirão do Ouro em Araraquara, São Paulo, obteve como coeficiente de desoxigenação $\left(\mathrm{K}_{1}\right)$ um valor médio de $0,40 \mathrm{~d}^{-1}$ e para o coeficiente de reaeração $\left(\mathrm{K}_{2}\right)$ um valor de $10,5 \mathrm{~d}^{-1}$. Estudando a modelagem do Rio Poti, no Estado do Piauí, Oliveira Filho (2014) encontrou $\mathrm{K}_{2}$ igual a 3,44 $\mathrm{d}^{-1}$ e coeficientes de decomposição da DBO $\left(\mathrm{K}_{\mathrm{d}}\right)$ e do decaimento bacteriano $\left(\mathrm{K}_{\mathrm{b}}\right)$ iguais a $0,85 \mathrm{~d}^{-1}$ e $0,5 \mathrm{~d}^{-1}$, respectivamente.
Dessa forma, o modelo QUAL-UFMG vem se mostrando uma ferramenta precisa e indispensável para a composição de qualquer sistema de monitoramento da qualidade de água. Mendes (2014) enalteceu os resultados satisfatórios que esse arquétipo proporcionou para a gestão e geração de cenários para a Bacia Hidrográfica do Rio Jaguaribe, Ceará. Somando a ele um banco de dados de qualidade de água consistente e um correto e atualizado mapeamento do uso e ocupação do solo, a gestão dos recursos hídricos no semiárido será mais eficiente, eficaz e racional.

Portanto, a proposta deste artigo foi aplicada ao Açude Acarape do Meio, que, além de ter uma influência na qualidade da água do sistema que mantém a segurança hídrica de toda a Região Metropolitana de Fortaleza (RMF), é responsável pelo abastecimento humano de seis sedes municipais e do segundo maior parque industrial do Estado do Ceará. Sendo assim, esta pesquisa teve como objetivo principal efetuar o diagnóstico, a avaliação da qualidade da água e a classificação dos corpos hídricos da microbacia do Açude Acarape do Meio no semiárido cearense como plataforma básica para um futuro processo de enquadramento dos corpos hídricos daquela bacia.

\section{METODOLOGIA}

Para um efetivo diagnóstico da Bacia Hidrográfica do Açude Acarape do Meio, cuja área é de $240 \mathrm{~km}^{2}$, foi realizado um levantamento do uso e da ocupação do solo, por meio da aplicação de um questionário junto às instituições e aos órgãos públicos localizados na região da bacia. Além disso, foram levantados em campo aproximadamente 300 pontos usando um GPS portátil, entre outros pontos, para identificação das fontes poluidoras pontuais e difusas, as quais foram mapeadas utilizando o software ArcGIS.

Essa pequena bacia é formada por uma rede de drenagem, que tem no Rio Pacoti sua principal calha, com uma extensão aproximada de $37 \mathrm{~km}$, e uma área que representa $80 \%$ da área total da bacia, desde sua nascente até a entrada do Reservatório Acarape do Meio, com alguns tributários, além de outros 3 pequenos riachos, o Canabrava com 9,67 km, o Brenha com 4,0 km e o Calção com 3,7 km de extensão, totalizando $20 \%$ da área total da bacia (ver Figura 1). Para o controle e o monitoramento da qualidade da água, foram instaladas oito seções de controle para a medição de vazão diária no período chuvoso e coleta mensal de água para análise dos parâmetros OD, DBO, fósforo total e coliformes termotolerantes.

A distribuição das seções atendeu aos seguintes critérios: quatro no Rio Pacoti, duas no Riacho Canabrava, uma no Riacho Brenha e uma no Riacho Calção. As seções foram instaladas antes e depois de uma fonte poluidora. No Rio Pacoti, com quatro seções:

1. a primeira localizou-se na nascente daquele rio;

2. a segunda foi instalada após a sede municipal de Pacoti e a jusante de duas Estações de Tratamentos de Esgoto (ETEs) daquele município; 
3. a terceira seção ficou logo após uma expressiva área agrícola de horticultura da região;

4. e a última seção ficou na entrada do açude Acarape do Meio e logo após a entrada de um expressivo tributário, o Riacho Salgado, região em que a atividade principal é a pecuária.

A primeira seção de controle no Riacho Canabrava foi instalada após uma ETE na sede municipal de Palmácia e a outra seção ficou próxima à entrada do açude já mencionado, da mesma forma que as seções dos Riachos Brenha e Calção ficaram na entrada do Açude Acarape do Meio, para a estimativa da carga de fósforo que entrava naquele reservatório (Figuras 1 e 2).

Para a medição de vazão nas seções de controle, foram instaladas réguas linimétricas e colhidas suas leituras diárias. Com o medidor de vazão tipo FlowTracker foram tomadas cinco medições após o registro de precipitação no período chuvoso. Os dados de vazão diária foram colhidos durante os anos de 2013 e 2014 em seus respectivos períodos chuvosos, dos quais foi possível traçar a curva-chave.

Do mesmo modo foram obtidos os dados de qualidade de água nas seções de controle para o mesmo período a partir da análise dos parâmetros $\mathrm{OD}, \mathrm{DBO}$, fósforo total e coliformes termotolerantes, que alimentaram o modelo QUAL-UFMG, a partir da média dos dados daquele período, sendo que, para a calibração do respectivo modelo, foram utilizados os dados médios de 2014 e para a validação os dados médios do ano de 2013.
Como o modelo QUAL-UFMG é oriundo do QUAL2E, ele utiliza equações matemáticas para qualidade de água de rios, conforme a equação unidimensional de transporte de massa, que é dada pela Equação 1.

$\frac{\partial c}{\partial t}+U \frac{\partial c}{\partial t}=\varepsilon \frac{\partial^{2} c}{\partial X^{2}}-k C$

Em que:

$\mathrm{C}=$ concentração do constituinte $\left(\mathrm{mg} \cdot \mathrm{L}^{-1}\right)$;

$\mathrm{U}=$ velocidade média da água $\left(\mathrm{m} . \mathrm{s}^{-1}\right)$;

$\varepsilon=$ difusividade do constituinte na água $\left(\mathrm{m}^{2} \cdot \mathrm{s}^{-1}\right)$;

$\mathrm{X}=$ coordenada longitudinal $(\mathrm{m})$;

$k=$ coeficiente de reação de primeira ordem $\left(\mathrm{d}^{-1}\right)$.

No entanto, o QUAL-UFMG considera a aproximação de fluxo em pistão, na qual são desprezados os termos transiente e de difusão na Equação 1, sendo $t=X / U$ definido como o tempo de translado.

Logo, para o parâmetro DBO, pode-se descrever o processo de decomposição da matéria orgânica no rio por meio de uma reação de primeira ordem (Equação 2):

$\frac{d L}{d t}=-K_{d} \cdot L$

Em que:

$\mathrm{L}=$ concentração da DBO (mg. $\left.\mathrm{L}^{-1}\right)$;

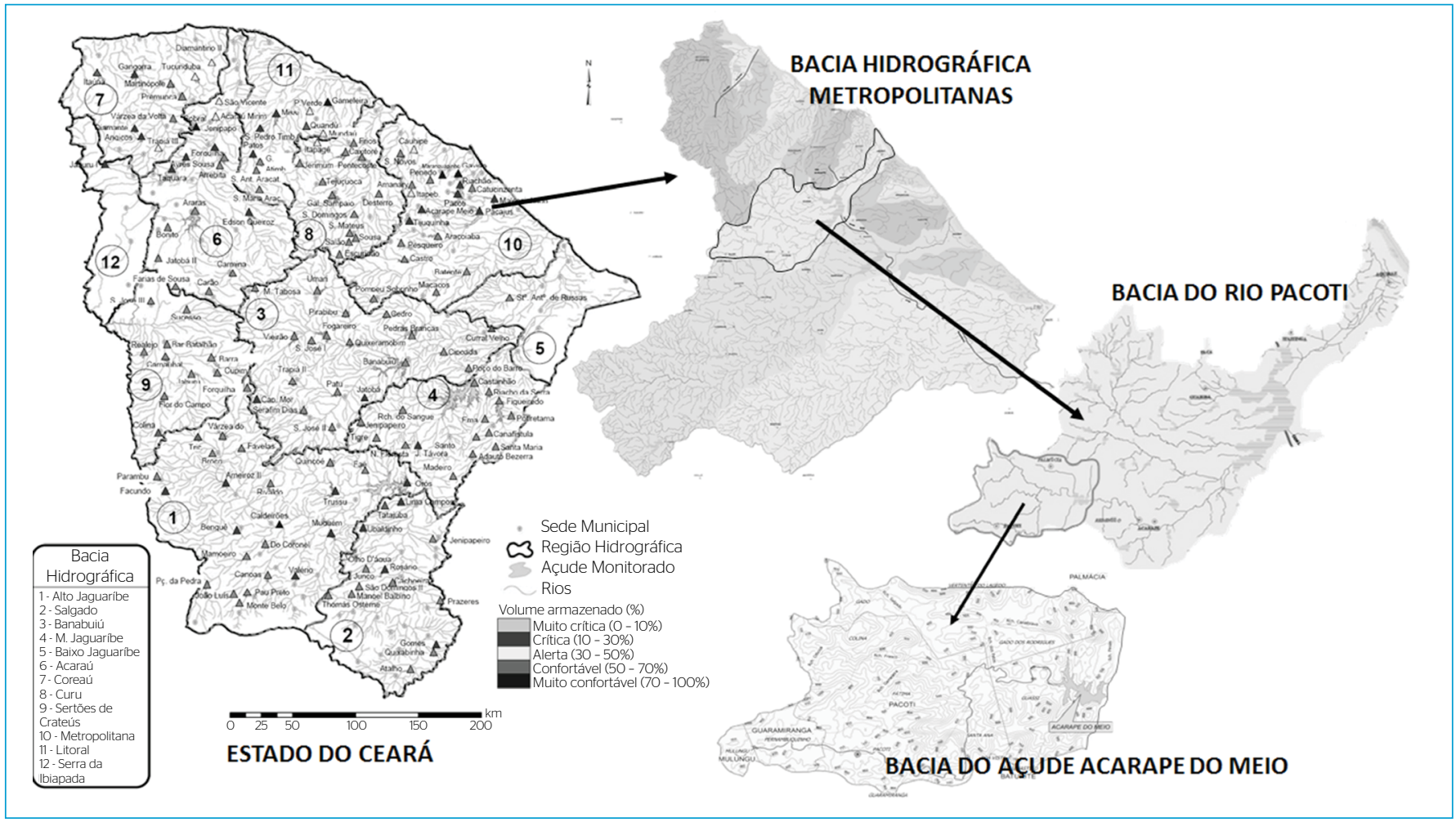

Figura 1 - Localização da área em estudo. 
$\mathrm{Kd}=$ coeficiente de decomposição da matéria orgânica no rio $\left(\mathrm{d}^{-1}\right)$; $\mathrm{t}=$ tempo (dias).

A cinética do OD, denominada de cinética da reaeração, pode ser descrita pela Equação 3:

$\frac{d C}{d t}=-K_{2} \cdot(C s-C)$

Em que:

Cs-C = déficit de OD (mg. $\left.\mathrm{L}^{-1}\right)$;

$\mathrm{K}_{2}=$ coeficiente de reaeração $\left(\mathrm{d}^{-1}\right)$;

$\mathrm{t}=$ tempo (dias).

As cinéticas de fósforo orgânico e inorgânico representam o modelo do fósforo, conforme descrito pelas Equações 4 e 5 :

Fósforo orgânico

$\frac{d \text { Porg }}{d t}=-K_{O i} \cdot P_{o r g}-K_{s p o} \cdot P_{o r g}$

Fósforo inorgânico

$d \frac{P_{\text {inor }}}{d t}=-K_{O i} \cdot P_{\text {org }}+S_{\text {Pinor }} / H$

Em que:

$\mathrm{P}_{\mathrm{org}}=$ concentração de fósforo orgânico $\left(\mathrm{mg} \cdot \mathrm{L}^{-1}\right)$;
$\mathrm{P}_{\text {inor }}=$ concentração de fósforo inorgânico $\left(\mathrm{mg} \cdot \mathrm{L}^{-1}\right)$;

$\mathrm{K}_{\text {spo }}=$ coeficiente de remoção de fósforo orgânico por sedimentação $\left(\mathrm{d}^{-1}\right)$;

$\mathrm{K}_{\mathrm{oi}}=$ coeficiente de conversão do fósforo orgânico a fósforo inorgânico $\left(\mathrm{d}^{-1}\right)$; $\mathrm{S}_{\text {Pinor }}=$ coeficiente de liberação do fósforo pelo sedimento de fundo $\left(\mathrm{gO}_{2} \cdot \mathrm{m}^{-2} \cdot \mathrm{d}^{-1}\right)$;

$\mathrm{H}=$ profundidade do rio $(\mathrm{m})$.

A cinética do decaimento bacteriano retrata a taxa de mortalidade bacteriana e é avaliada por meio da Equação 6:

$\frac{d N}{d t}=-K_{b} \cdot N$

Em que:

$\mathrm{N}$ = número de coliformes (org/100 $\mathrm{ml}$ ou $\mathrm{NMP}$ - número mais provável); $\mathrm{Kb}=$ coeficiente de decaimento bacteriano $\left(\mathrm{d}^{-1}\right)$; $\mathrm{t}=$ tempo (dias).

Os coeficientes hidráulicos solicitados pela planilha QUAL-UFMG foram obtidos a partir de um valor médio, pela correlação da vazão com a velocidade do escoamento e da vazão com a profundidade do escoamento na seção. Os outros dados para o trecho inicial do Rio Pacoti, tais como vazão, $\mathrm{OD}, \mathrm{DBO}$, fósforo (orgânico, inorgânico e total) e coliformes termotolerantes, foram definidos como os dados médios da estação chuvosa na primeira seção de controle do citado rio, denominada de seção Pernambuquinho ou Califórnia.

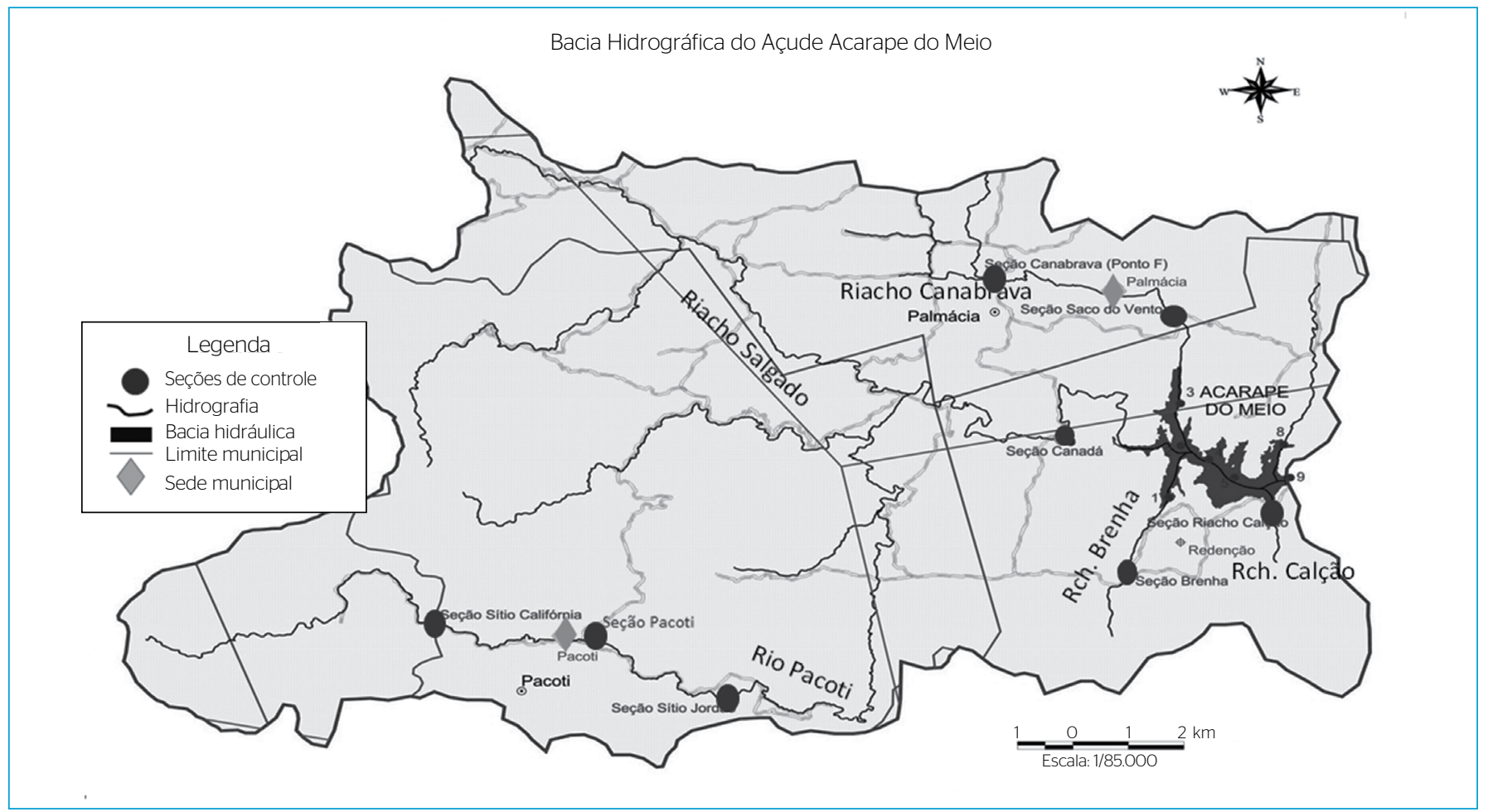

Figura 2 - Localização da bacia do Açude Acarape do Meio e as seções de controle. 
Com o reconhecimento das poluições pontuais, tais como ETE, matadouros e áreas concentradas de agricultura, foram escolhidos os parâmetros a serem modelados pelo QUAL-UFMG, bem como os valores de vazão média. Particularmente nas áreas irrigadas foram tomados o volume de água aplicada e a estimativa da vazão de drenagem. Esses valores foram inseridos nos pontos de entrada a partir do diagrama unifilar, como parte de uma das quatro planilhas do modelo QUAL-UFMG.

Para a calibração do modelo QUAL-UFMG, lançou-se mão da ferramenta SOLVER do Excel, com o objetivo de se obter o melhor valor para o coeficiente de Nash-Sutcliffe $\left(\mathrm{C}_{\mathrm{NS}}\right)$, conforme Equação 7, para os respectivos coeficientes da cinética de $\mathrm{OD}, \mathrm{DBO}$, fósforo e coliformes termotolerantes. $\mathrm{O}$ coeficiente $\mathrm{C}_{\mathrm{NS}}$ é uma medida de ajustamento do modelo de forma a indicar quanto esse modelo explica os valores observados.

$C N S=1-\frac{\sum\left[Y_{o b s}-Y_{e s t}\right]^{2}}{\sum\left[Y_{o b s}-Y_{o b s m e d}\right]^{2}}$

Em que:

$Y_{\text {obs }}=$ parâmetro de qualidade da água observado em campo;

Yest $=$ dado estimado pelo modelo; $\mathrm{e}$

Yobsmed $=$ média dos valores observados

Com os coeficientes calibrados, efetuou-se a validação do modelo. Com o processo de modelagem, foram testados dois cenários na bacia, simulando o parâmetro fósforo total:

1. o primeiro seria a redução da carga de fósforo por parte das fontes poluidoras em $50 \%$, incluindo as ETEs e a carga gerada pelas atividades agropecuárias;

2. o segundo cenário consiste em possibilitar que apenas as ETEs do Rio Pacoti possam ter uma eficiência de $85 \%$ de remoção, sem efetuar qualquer outra redução nas demais fontes poluidoras.

\section{RESULTADOS E DISCUSSÃO}

A partir do diagnóstico da bacia e da estimativa da produção de fósforo com base nas equações empíricas de Von Sperling (2003), foi possível estimar a situação precária do saneamento básico, principalmente na zona rural, de acordo com os dados mostrados na Tabela 1. É importante informar que os dados na citada Tabela 1 são predominantemente da zona rural, em cuja área residem $69 \%$ da população total. Diante desses números é possível perceber que não há nenhum sistema de saneamento básico no campo, sendo que $95,7 \%$ dessa população ou não têm banheiros, ou apresentam tão somente fossas rudimentares, o que ocasiona o lançamento de esgoto bruto diretamente no meio ambiente, produzindo uma considerável carga de fósforo, DBO e coliformes termotolerantes. A zona urbana, que é caracterizada pelas sedes municipais de Pacoti e Palmácia, traz um considerável número de pessoas ligadas ao sistema de coleta de esgoto formado por três ETEs - Pau do Alho e 13 de Maio, no município de Pacoti, e Palmácia, no município homônimo. No entanto, essas ETEs se mostram totalmente deficitárias, o que as torna muito mais danosas do que o esgoto bruto lançado pela população da zona rural, pois essa fonte poluidora se caracteriza como poluição difusa, cujo efeito é mais lento ao meio ambiente.

Ainda tomando por base as equações empíricas para estimativa do cálculo da carga de fósforo difusa por Von Sperling (2003), nas atividades agropecuárias (Tabelas 2 e 3 ) é possível observar que na agricultura a produção agrícola de sequeiro representou a maior área plantada, contribuindo, assim, para a maior produção da carga de fósforo para essa atividade, por conta do uso da adubação química e orgânica sem uma adequada assistência técnica, conforme os questionários aplicados. No tocante à atividade pecuária, os rebanhos bovino e suíno produziram a maior carga de coliformes termotolerantes. O número de animais da Tabela 3 foi convertido para unidade animal, por isso que a produção diária de dejetos teve o mesmo valor: 8,5 kg.cab.d ${ }^{-1}$.

Com a calibração do modelo, foi possível alcançar os devidos ajustes dos coeficientes para OD, DBO, fósforo e coliformes termotolerantes. Para o coeficiente de desoxigenação $\left(\mathrm{K}_{1}\right)$, o valor foi de $0,45 \mathrm{~d}^{-1}$, representando um valor de $\mathrm{C}_{\mathrm{NS}}$ de 0,56 , considerado bom de acordo com a classificação de Moriase et al. (2007). O valor calibrado de $\mathrm{K}_{1}$ ficou bem próximo ao encontrado por Costa e Teixeira (2010), que foi de $0,40 \mathrm{~d}^{-1}$ para uma bacia na Região Sudeste. Isso se deve ao fato de que em ambos os casos as ETEs se comportaram como fontes pontuais de poluição cujos efluentes estão fora das normas estabelecidas pela Resolução CONAMA n 430/2011. Salla et al. (2013) encontraram para $\mathrm{K}_{1}$ um valor de $0,03 \mathrm{~d}^{-1}$, isso se deve provavelmente ao fato de não ter sido localizada qualquer fonte poluidora pontual.

Tabela 1 - Saneamento básico e cálculo empírico para carga de fósforo produzida na área da bacia.

\begin{tabular}{l|c|c|c|c|c|c|c} 
População & $\begin{array}{c}\text { Esgoto Bruto } \\
\text { (hab) }\end{array}$ & $\begin{array}{c}\text { Fossa } \\
\text { Rudimentar (hab) }\end{array}$ & $\begin{array}{c}\text { Fossa Séptica } \\
\text { (hab) }\end{array}$ & $\begin{array}{c}\text { Rede de Esgoto } \\
\text { (hab) }\end{array}$ & $\begin{array}{c}\text { Produção P na } \\
\text { bacia (Ced) (ton/ano) }\end{array}$ & $\begin{array}{c}\text { Produção P no rio } \\
\text { (Cedma) (ton/ano) }\end{array}$ & $\begin{array}{c}\text { Produção P no rio } \\
\text { Fossa Verde (ton/ano) }\end{array}$ \\
\hline Urbana & 915 & 3.956 & 883 & 4.032 & 5,87 & 5,29 & 2,28 \\
\hline Rura & 11.490 & 9.242 & 929 & 0 & 8,66 & 8,53 & 0,87 \\
\hline Total & 12.405 & 13.198 & 1.812 & 4.032 & 14,54 & 13,83 & \\
\hline
\end{tabular}

Ced: Carga de fósforo doméstico; Cedma: Carga que chega ao meio ambiente. 
No caso do coeficiente $\mathrm{K}_{2}$, esta pesquisa calculou um valor de 5,4 $\mathrm{d}^{-1}$, enquanto Oliveira Filho (2014) encontrou um valor de 3,44 $\mathrm{d}^{-1}$ para condições semelhantes no Rio Poti, no Estado do Piauí. Salla et al. (2013), para o Rio Jordão em Minas Gerais, obtiveram um valor de $0,22 \mathrm{~d}^{-1}$ para o $\mathrm{K}_{2}$, apesar de se tratar de um rio raso e com velocidade considerável, o que se esperaria valores maiores. Quanto ao coeficiente $\mathrm{K}_{\mathrm{s}}$, foi encontrado um valor de $0,29 \mathrm{~d}^{-1}$. Esse valor se mostrou coerente, pois, conforme Von Sperling (2007), o valor de $\mathrm{K}_{\mathrm{s}}$ é inversamente proporcional à profundidade do rio, sendo assim, quanto mais profundo um rio, menor $\mathrm{o}$ valor de $\mathrm{K}_{\mathrm{s}}$. No entanto, em relação à presença de fontes poluidoras pontuais, como ETEs deficitárias, esse valor tende a ser mais expressivo.

Quanto ao valor $\mathrm{K}_{\mathrm{d}}$, esta pesquisa encontrou $0,68 \mathrm{~d}^{-1}$. O modelo conseguiu explicar $93 \%$ dos valores observados, ou seja, um valor de $\mathrm{C}_{\mathrm{NS}}$ igual a 0,93 , portanto muito bom, conforme a classificação de Moriasi $e t$ al. (2007). Comparando com outras pesquisas, para as condições do Rio Poti no Piauí, Oliveira Filho (2014) alcançou um valor de $0,85 \mathrm{~d}^{-1}$, o que confirma a condição de rios rasos para ambas as condições. Mendes (2014), para o Rio Jaguaribe, achou 0,09 $\mathrm{d}^{-1}$, valor coerente para um rio profundo. No caso do coeficiente de decaimento bacteriano $\left(\mathrm{K}_{\mathrm{b}}\right)$, localizou-se um valor ajustado de $0,65 \mathrm{~d}^{-1}$, bem próximo do valor de 0,50 $\mathrm{d}^{-1}$ obtido por Oliveira Filho (2014) para condições semelhantes no Rio Poti. Na pesquisa de Salla et al. (2013), o valor foi de $0,15 \mathrm{~d}^{-1}$ para as condições da Região Sudeste. Quanto ao valor de $\mathrm{C}_{\mathrm{NS}}$, ficou em 0,80, igualmente muito bom para a classificação de Moriasi et al. (2007).

Com o levantamento dos dados de qualidade de água nas seções monitoradas na bacia hidrográfica foi possível gerar o mapa das fontes poluidoras (Figura 3), que mostrou a existência de quatro ETEs na bacia em estudo, sendo três localizadas no Rio Pacoti, das quais uma se encontra desativada, ficando próxima à nascente do rio supracitado. As outras duas ETEs do Rio Pacoti estão localizadas na entrada da sede do município de Pacoti, denominada de Pau do Alho, e a outra na saída do município, denominada de 13 de Maio. A terceira ETE da bacia em estudo é conhecida por ETE Palmácia, localizada no município de Palmácia, que abriga o Riacho Canabrava. As ETEs são deficitárias, como mostram os dados médios de qualidade dos seus efluentes, conforme a Tabela 4.

Com o diagnóstico apresentado pela Figura 3, e a partir dos dados de qualidade de água que alimentaram as informações de entrada da planilha QUAL-UFMG (Tabelas 5 e 6), foi possível classificar cada trecho

Tabela 2 - Áreas agrícolas na bacia do Açude Acarape do Meio e estimativa da carga de fósforo para o ano de 2014.

\begin{tabular}{|c|c|c|c|c|c|c|c|c|}
\hline \multirow{2}{*}{ Cultura } & \multirow{2}{*}{ Área (ha) } & \multirow{2}{*}{ Tipo de solo } & \multicolumn{2}{|c|}{ Necessidade nutricional (kg/ha) } & \multirow{2}{*}{$\begin{array}{l}\text { \% não absorção } \\
\text { de P pela cultura }\end{array}$} & \multirow{2}{*}{$\begin{array}{c}\% \text { perda de } \mathrm{P} \\
\text { para o solo }\end{array}$} & \multirow{2}{*}{$\begin{array}{c}\text { Necessidade } \\
\text { nutricional (ton) }\end{array}$} & \multirow{2}{*}{$\begin{array}{l}\text { Cálculo carga P que } \\
\text { retorna (ton/ano) }\end{array}$} \\
\hline & & & Sequeiro & Irrigado & & & & \\
\hline Milho & 871,0 & Argiloso & 0,05 & 0,08 & 13,0 & 25 & 43,550 & 1,415 \\
\hline Feijão & 584,0 & Arenoso & 0,06 & 0,06 & 6,0 & 25 & 35,040 & 0,526 \\
\hline Algodão & 100,0 & Arenoargiloso & 0,05 & 0,07 & 1,1 & 6 & 5,000 & 0,003 \\
\hline Mandioca & 100,0 & Arenoargiloso & 0,05 & 0,05 & 5,0 & 1 & 5,000 & 0,003 \\
\hline Arroz & 972,0 & Arenoargiloso & 0,06 & 0,06 & 6,0 & 25 & 58,320 & 0,875 \\
\hline Café & $1.053,0$ & Arenoargiloso & 0,03 & 0,06 & 5,0 & 1 & 31,590 & 0,016 \\
\hline Banana & $3.279,0$ & Arenoargiloso & 0,03 & 0,03 & 5,0 & 1 & 98,370 & 0,049 \\
\hline Manga & 100,0 & Arenoargiloso & 0,03 & 0,03 & 5,0 & 1 & 3,000 & 0,002 \\
\hline Maracujá & 8,5 & Arenoargiloso & 0,03 & 0,03 & 40,0 & 40 & 0,255 & 0,041 \\
\hline Hortaliças & 27,4 & Arenoargiloso & 0,03 & 0,03 & 13,0 & 25 & 0,822 & 0,027 \\
\hline \multicolumn{8}{|l|}{ Total } & 2,956 \\
\hline
\end{tabular}

Fonte: IBGE, 2014

Tabela 3 - Rebanho de animais na bacia e a estimativa da carga de fósforo difusa.

\begin{tabular}{l|c|c|c|c|c} 
Rebanho & Cenário $(f)$ & $N^{0}$ de animais & Produção diária de dejetos (kg/cab.dia) & $\begin{array}{c}\text { Percentual médio de fósforo } \\
\text { nos dejetos (\%) }\end{array}$ & $\begin{array}{c}\text { Estimativa de produção de } \\
\text { fósforo (ton/ano) }\end{array}$ \\
\hline Bovino & 1 & 2193 & 8,5 & 0,35 & 23,81 \\
\hline Equino & 1 & & 8,5 & 0,35 & 0,00 \\
\hline Suíno & 1 & 601 & 8,5 & 0,30 & 5,60 \\
\hline Ovino & 1 & 170 & 8,5 & 0,50 & 2,64 \\
\hline Caprino & 1 & & 8,5 & 0,50 & 0,00 \\
\hline Galináceo & 1 & 491 & 8,5 & 1,30 & 19,79 \\
\hline Total & \multicolumn{7}{r}{} & & & 51,84 \\
\hline
\end{tabular}


do Rio Pacoti, bem como os Riachos Canabrava, Brenha e Calção, de acordo com a Resolução CONAMA n 357/2005 (Figura 4).

Obedecendo ao que foi descrito na metodologia para a calibração dos coeficientes $\mathrm{K}_{1}, \mathrm{~K}_{\mathrm{d}}, \mathrm{K}_{\text {spo }}, \mathrm{K}_{\mathrm{b}}, \mathrm{K}_{2}, \mathrm{~K}_{\mathrm{S}}$ e $\mathrm{K}_{\mathrm{oi}}$, foram obtidos, respectivamente, os seguintes valores: $0,45 \mathrm{~d}^{-1}, 0,68 \mathrm{~d}^{-1}, 0,1 \mathrm{~d}^{-1}, 0,65 \mathrm{~d}^{-1}, 5,4 \mathrm{~d}^{-1}, 0,29 \mathrm{~d}^{-1}$ e $0,01 \mathrm{~d}^{-1}$, que foram usados para a validação do modelo.

Sobre a classificação do corpo hídrico, o trecho de $37 \mathrm{~km}$ do Rio Pacoti ficou classificado como classe 4, salvo o trecho da sua nascente, que permaneceu na classe 2 . Os outros três riachos também foram classificados como classe 4, ou seja, água imprópria para o abastecimento humano. Somente o trecho do Riacho Salgado foi classificado a partir da estimativa de carga de fósforo pelas equações empíricas de Von Sperling (2003). As águas que aportam no Açude Acarape do Meio são oriundas desse trecho do Rio Pacoti e dos três riachos identificados, consequentemente o reservatório estará classificado como classe 4, principalmente para o parâmetro fósforo. Nos riachos, o que causou maior impacto foi a ausência de saneamento básico da zona rural.

Conforme a Resolução CONAMA n 430/2011, que dispõe sobre as condições e os padrões de lançamento de efluentes, o artigo 21 trata do lançamento dos sistemas de tratamento de esgotos sanitários, indicando como valor máximo de DBO $120 \mathrm{mg} . \mathrm{L}^{-1}$. No entanto, a Tabela 3 mostra que as ETEs 13 de Maio e Pau do Alho estão fora dos padrões. Considerando que a Resolução CONAMA nº 357/2005 determina que a classe 2 seja um corpo hídrico destinado ao abastecimento humano, apresenta limite máximo de coliformes termotolerantes de 1.000 NMP por $100 \mathrm{~mL}$, o que se observa é que as ETEs 13 de Maio e Palmácia estão lançando nos corpos hídricos mais de $2,2 \times 10^{6} \mathrm{NMP}$ por $100 \mathrm{~mL}$ de coliformes termotolerantes. Quanto à concentração de fósforo total para a classe 2, a citada resolução indica como limite máximo $0,1 \mathrm{mg} \cdot \mathrm{L}^{-1}$;

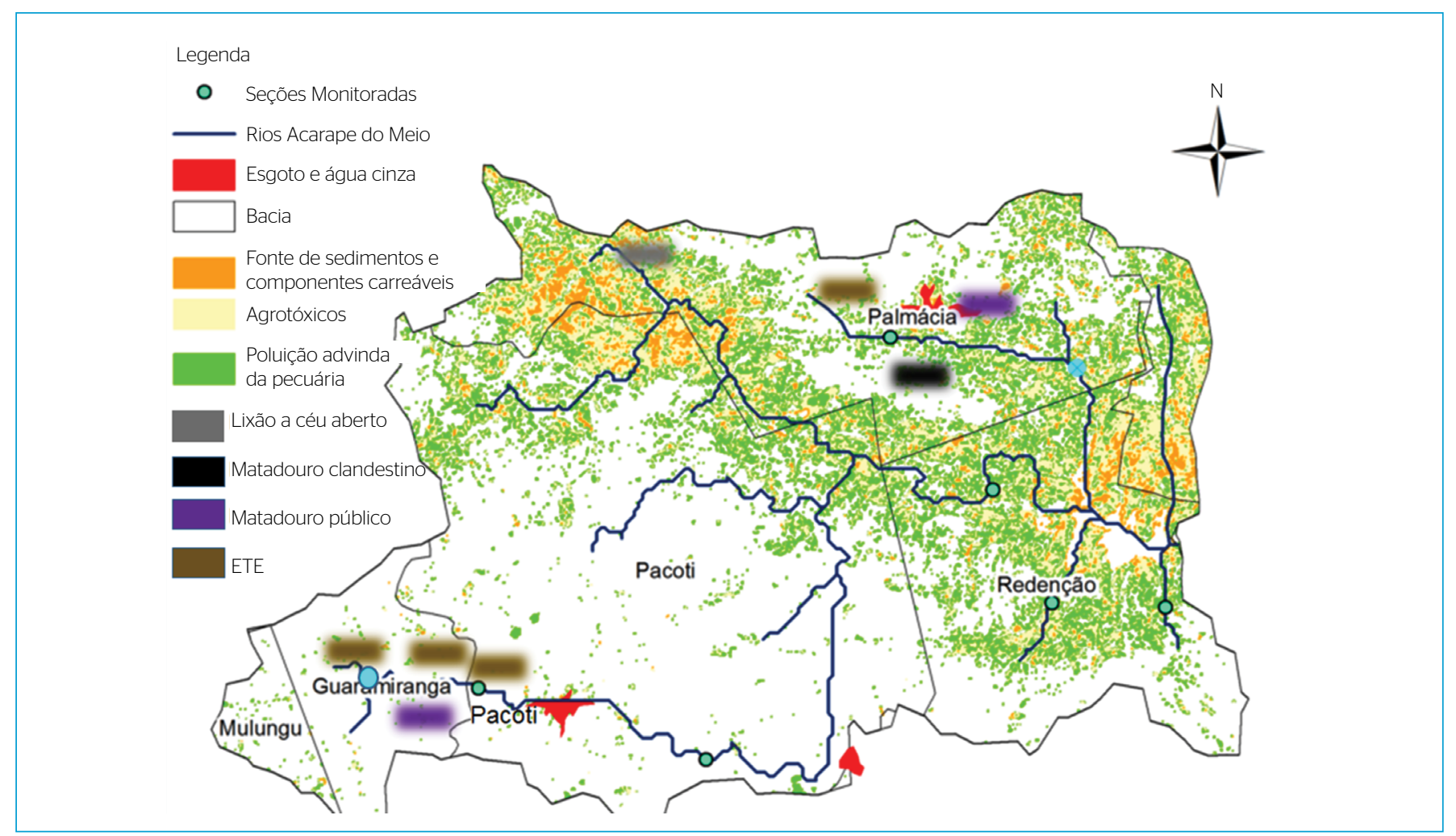

Figura 3 - Fontes poluidoras na bacia hidrográfica do Açude Acarape do Meio.

Tabela 4 - Média aritmética dos valores dos parâmetros químicos nas Estações de Tratamento de Esgoto - 2014.

\begin{tabular}{|c|c|c|c|c|c|}
\hline \multirow{2}{*}{ Parâmetro } & \multicolumn{3}{|c|}{ ETEs - Valores médios (2014) } & \multirow{2}{*}{$\begin{array}{l}\text { Padrão de lançamento - Resolução } \\
\text { CONAMA nº } 430\end{array}$} & \multirow{2}{*}{$\begin{array}{l}\text { Padrão de lançamento - Portaria } \\
\text { nº 154/2002 SEMACE }\end{array}$} \\
\hline & 13 de Maio & Alho & Palmácia & & \\
\hline $\mathrm{OD}(\mathrm{mg} / \mathrm{L})$ & 2,62 & 3,30 & 1,49 & & $>3.0$ \\
\hline $\mathrm{PT}(\mathrm{mg} / \mathrm{L})$ & 14,78 & 29,60 & 18,95 & & \\
\hline COLI (NMP/10O mL) & 2254730 & 44197 & 2259000 & & 5000 \\
\hline
\end{tabular}

OD: oxigênio dissolvido; DBO: demanda bioquímica de oxigênio; PT: fósforo total; COLI: coliformes. 
no entanto, foi registrado um lançamento de $14,78 \mathrm{mg} . \mathrm{L}^{-1}$ de fósforo total na ETE 13 de Maio no Rio Pacoti.

A aplicação do modelo QUAL-UFMG possibilitou verificar que o Rio Pacoti não conseguiu se autodepurar até a entrada do Açude Acarape do Meio, para uma vazão média observada de $1,48 \mathrm{~m}^{3} \cdot \mathrm{s}^{-1}$ registrada durante a quadra chuvosa de 2014 (período que vai de fevereiro a maio).
Vale destacar que se trata de um rio intermitente, ou seja, apresenta fluxo apenas em seis meses do ano, ficando o segundo semestre normalmente sem registro de vazão. O modelo confirmou que as ETEs são ineficientes quanto à sua capacidade de remoção de substâncias poluidoras.

A calibração do modelo com os dados observados em relação aos elementos simulados gerou $\mathrm{C}_{\mathrm{NS}}$ de $0,56,0,93,0,80$ e 0,80 para OD, $\mathrm{DBO}$,

Tabela 5 - Dados médios de entrada para o ano de 2014 (calibração).

\begin{tabular}{|c|c|c|c|c|c|c|c|c|c|c|}
\hline \multirow[b]{2}{*}{ Seção monitorada } & \multicolumn{5}{|c|}{ Dados medidos } & \multicolumn{5}{|c|}{ Dados de fontes poluidoras } \\
\hline & $\begin{array}{l}\text { q inicial } \\
\left(\mathrm{m}^{3} / \mathrm{s}\right)\end{array}$ & $\begin{array}{l}\mathrm{OD} \\
(\mathrm{mg} / \mathrm{L})\end{array}$ & $\begin{array}{l}\mathrm{DBO} \\
(\mathrm{mg} / \mathrm{L})\end{array}$ & $P(\mathrm{mg} / \mathrm{L})$ & $\begin{array}{c}\text { COLI } \\
\text { (NMP/ 10Oml) }\end{array}$ & $\begin{array}{l}\text { q inicial } \\
\left(\mathrm{m}^{3} / \mathrm{s}\right)\end{array}$ & $\begin{array}{c}\mathrm{OD} \\
(\mathrm{mg} / \mathrm{L})\end{array}$ & $\begin{array}{c}\mathrm{DBO} \\
(\mathrm{mg} / \mathrm{L})\end{array}$ & $P(\mathrm{mg} / \mathrm{L})$ & $\begin{array}{c}\text { COLI } \\
\text { (NMP/ 100ml) }\end{array}$ \\
\hline Pernambuquinho & 0,009 & 5,37 & 9,530 & 0,114 & 2662 & & & & & \\
\hline Pacoti & 0,158 & 3,29 & 33,500 & 3,900 & 420153 & 0,030 & 2,62 & 160,72 & 14,780 & 2254730 \\
\hline Jordão & 0,376 & 3,05 & 8,200 & 0,605 & 2941 & 0,006 & & & 0,071 & \\
\hline Salgado & 0,753 & & & & & 0,345 & & & 1,176 & \\
\hline Canadá & 1,480 & 6,13 & 5,6 & 0,6271 & 32848 & & & & & \\
\hline
\end{tabular}

OD: oxigênio dissolvido; DBO: demanda bioquímica de oxigênio; P: fósforo; COLI: coliformes.

Tabela 6 - Dados médios de entrada para o ano de 2013 (validação).

\begin{tabular}{|c|c|c|c|c|c|c|c|c|c|c|}
\hline \multirow[b]{2}{*}{ Seção monitorada } & \multicolumn{5}{|c|}{ Dados medidos } & \multicolumn{5}{|c|}{ Dados de fontes poluidoras } \\
\hline & $\begin{array}{l}\text { q inicial } \\
\left(\mathrm{m}^{3} / \mathrm{s}\right)\end{array}$ & $\begin{array}{c}\mathrm{OD} \\
(\mathrm{mg} / \mathrm{L})\end{array}$ & $\begin{array}{c}\text { DBO } \\
(\mathrm{mg} / \mathrm{L})\end{array}$ & $P(\mathrm{mg} / \mathrm{L})$ & $\begin{array}{c}\text { COLI } \\
\text { (NMP/10Oml) }\end{array}$ & $\begin{array}{l}\text { q inicial } \\
\left(\mathrm{m}^{3} / \mathrm{s}\right)\end{array}$ & $\begin{array}{c}\mathrm{OD} \\
(\mathrm{mg} / \mathrm{L})\end{array}$ & $\begin{array}{l}\text { DBO } \\
(\mathrm{mg} / \mathrm{L})\end{array}$ & $P(\mathrm{mg} / \mathrm{L})$ & $\begin{array}{c}\text { COLI } \\
\text { (NMP/10Oml) }\end{array}$ \\
\hline Pernambuquinho & 0,005 & 5,52 & 1,70 & 0,478 & 462 & & & & & \\
\hline Pacoti & 0,134 & 3,33 & 33,70 & 5,964 & 525143 & 0,030 & 2,62 & 160,72 & 14,780 & 2254730 \\
\hline Jordão & 0,263 & 2,78 & 15,10 & 0,290 & 601 & 0,006 & & & 0,071 & \\
\hline Salgado & 0,366 & & & & & 0,129 & & & 2,340 & \\
\hline Canadá & 0,615 & 6,04 & 4,70 & 0,564 & 807 & & & & & \\
\hline
\end{tabular}

OD: oxigênio dissolvido; DBO: demanda bioquímica de oxigênio; P: fósforo; COLI: coliformes.

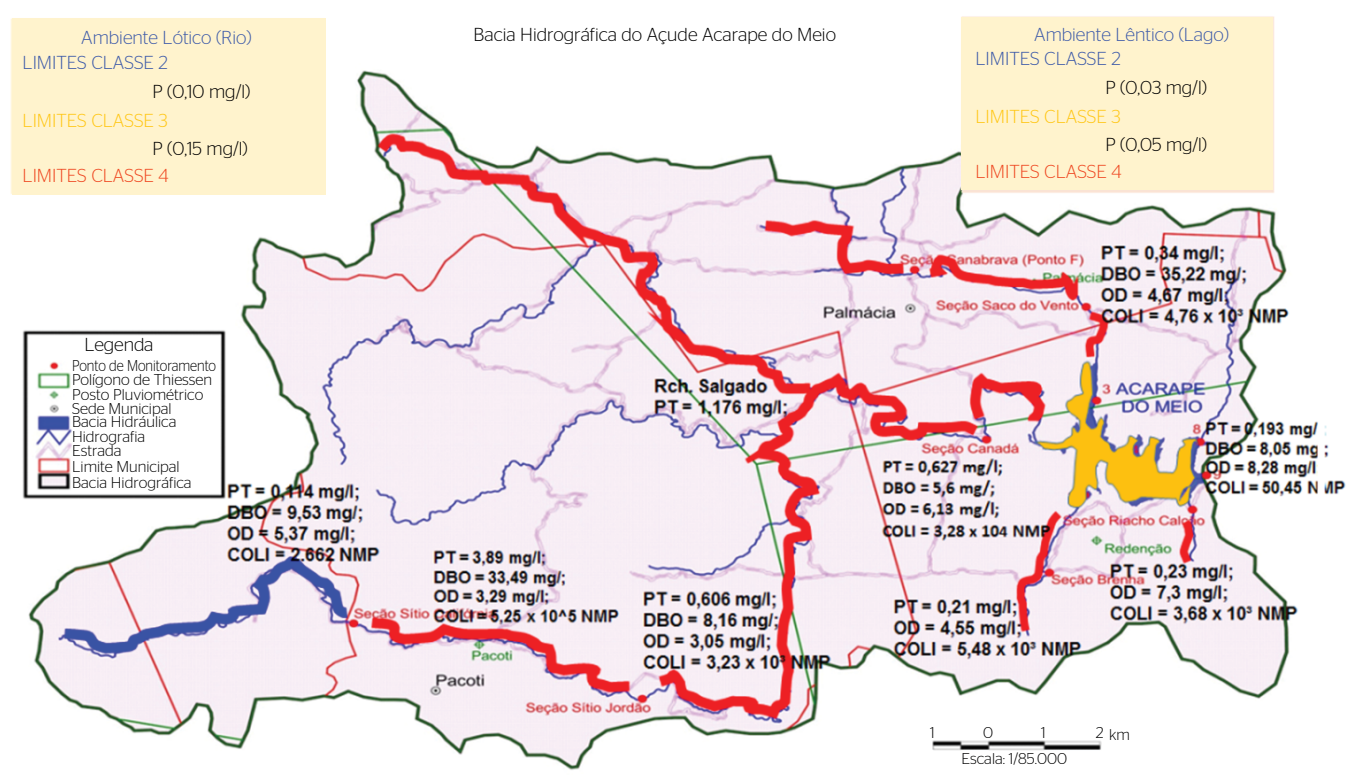

Figura 4 - Classificação dos corpos d’água na bacia do Açude Acarape do Meio. 
fósforo total e coliformes termotolerantes, respectivamente, mostrando bom desempenho do modelo (Figura 5). Para a validação, os valores de $\mathrm{C}_{\mathrm{NS}}$ ficaram em 0,58, 0,98, 0,68 e 0,72 para OD, DBO, fósforo total e coliformes termotolerantes, respectivamente, conforme Figura 6. Foram utilizados os dados médios de 2013, mas mantendo os valores ajustados dos coeficientes obtidos a partir dos dados modelados para o ano de 2014.

O resultado confirma um quadro de degradação ambiental bem acentuado na área, com lançamento de esgoto bruto diretamente no rio e nos

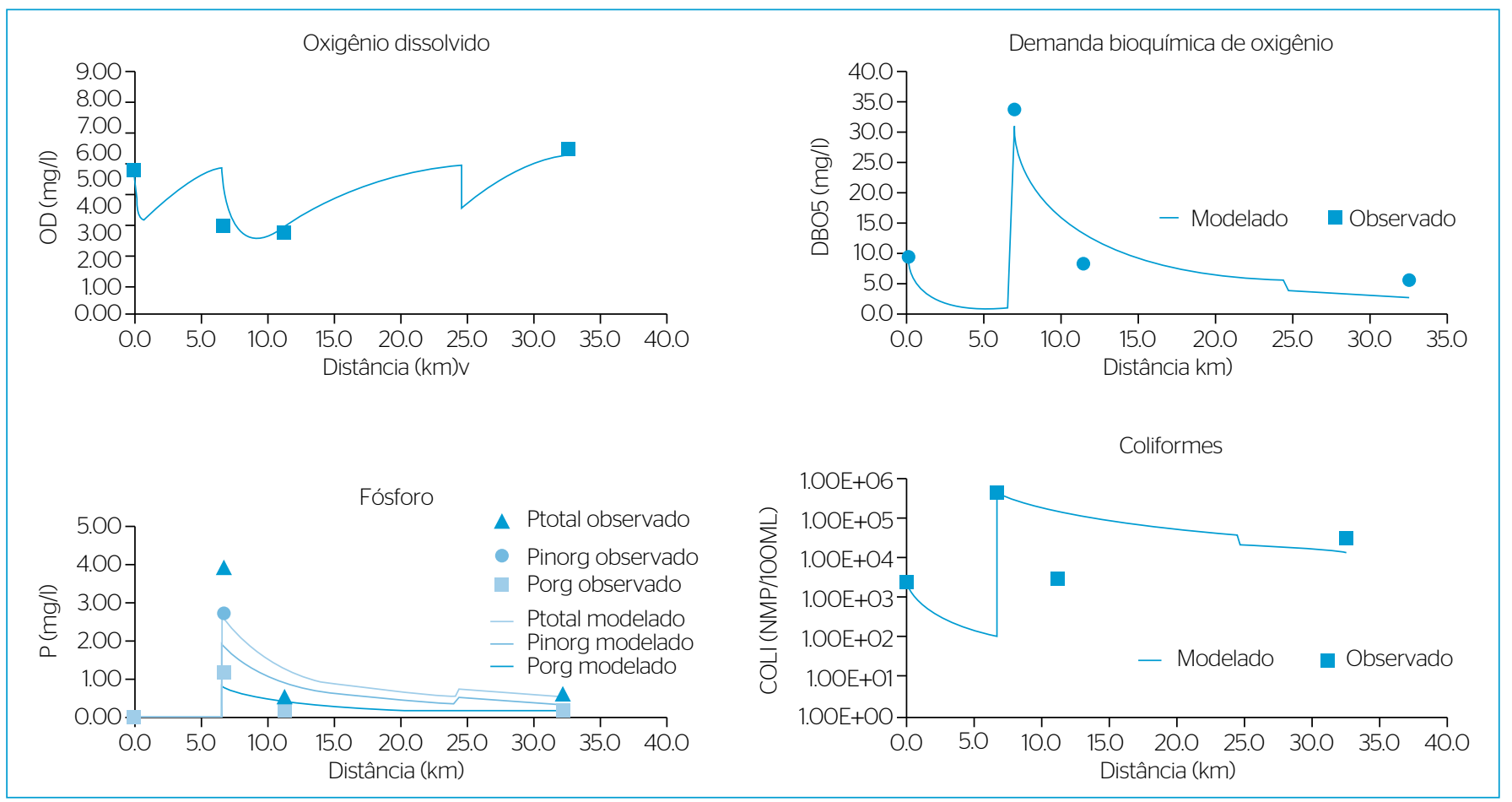

Figura 5 - Calibração dos dados simulados versus observados no ano de 2014 - modelo QUAL-UFMG.

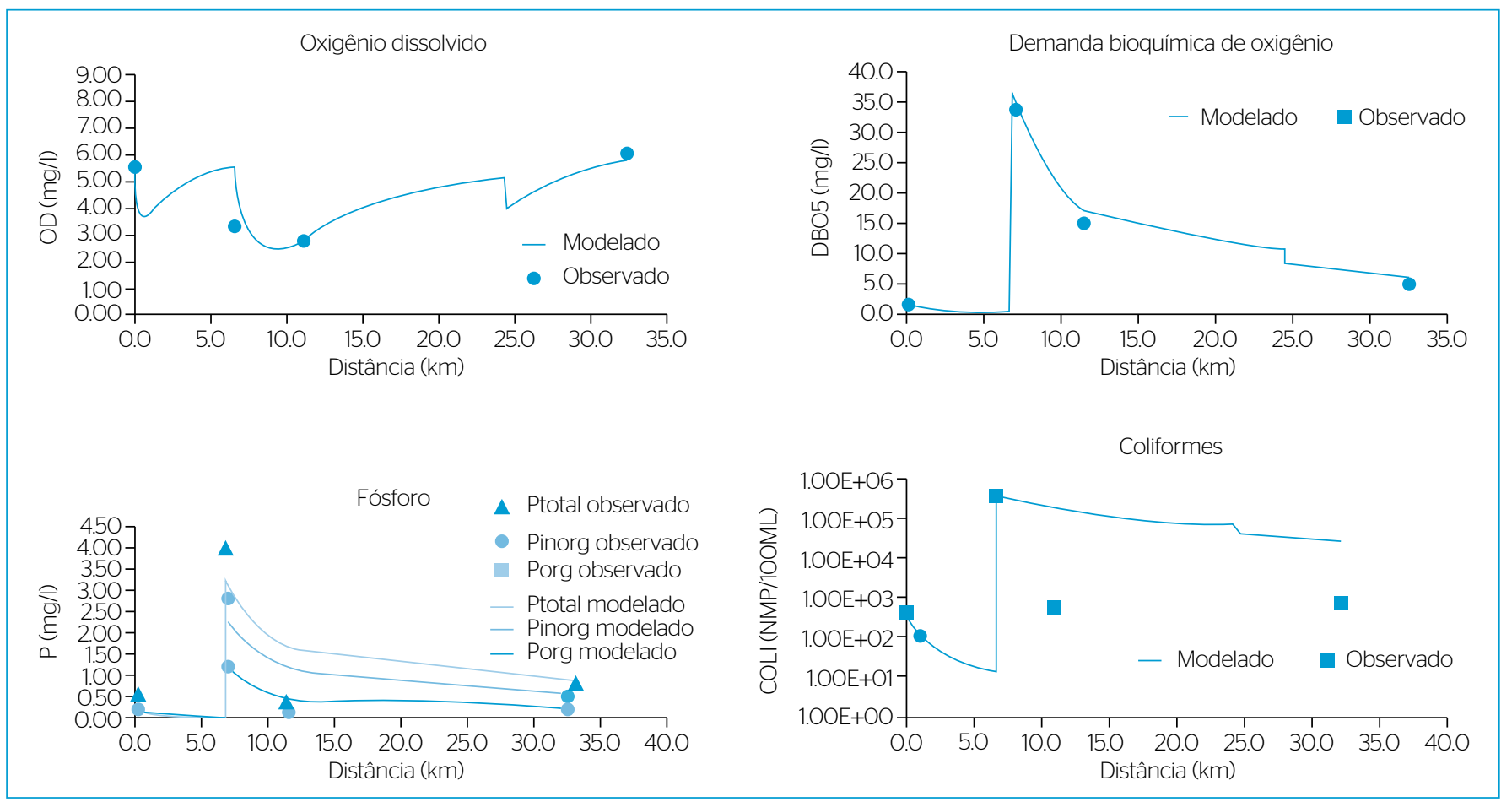

Figura 6 - Validação dos dados simulados versus observados para o ano de 2013 - modelo QUAL-UFMG. 
riachos da bacia em estudo. As ETEs, além de não tratarem os efluentes adequadamente, concentram o lançamento de esgoto em um único ponto da rede de drenagem próximo de sua localização. Outra fonte importante de degradação é constituída pelos rebanhos bovino e suíno, bem como pelos matadouros localizados na área, de acordo com o cálculo da carga por meio das equações empíricas propostas por Von Sperling (2003). Quanto ao parâmetro fósforo, esta pesquisa dispunha apenas do fósforo total; contudo, Von Sperling (2007), no seu livro Estudos e modelagem da qualidade da água de rios, no capítulo referente à modelagem do fósforo, afirma que o fósforo total pode ser fracionado em inorgânico e orgânico, cabendo à fração inorgânica o valor de 70\% do fósforo total, enquanto a fração orgânica representa $30 \%$ do fósforo total. Nos dados de fósforo total e orgânico apresentados no estudo de Pacheco (2009) para o Açude Acarape do Meio, a fração do fósforo orgânico representou uma média de $36 \%$ para os 7 pontos de coleta.

Após calibração e validação do modelo QUAL-UFMG, foi possível gerar cenários de intervenção apenas para o parâmetro fósforo, por entender que ele se mostrou como o melhor indicador das interferências antrópicas e ferramenta apropriada para controle das ações corretivas. O primeiro cenário foi a redução de $50 \%$ da concentração de fósforo em cada ponto de poluição, ou seja, ETEs mais eficientes por intermédio de um programa de investimento de recuperação, avanço do saneamento básico na zona rural com instalação de fossas verdes, práticas agrícolas sustentáveis e redução do rebanho em $50 \%$ ou uma prática que possa reter $50 \%$ dos dejetos, como instalação de biodigestores, tudo para um horizonte de até 20 anos, respeitando o Plano das Bacias Hidrográficas Metropolitanas e o Plano de Saneamento Básico dos municípios de Pacoti e Palmácia, que se encontram em fase de conclusão. Nesse cenário, a concentração de fósforo na última seção de controle do Rio Pacoti passaria de 0,56 para $0,27 \mathrm{mg} \cdot \mathrm{L}^{-1}$, gerando uma carga de entrada no reservatório de 6,8 ton.ano ${ }^{-1}$, bem inferior às 13,7 ton.ano ${ }^{-1}$ que atualmente aportam no reservatório, conforme o modelo QUAL-UFMG. Mesmo assim, o Rio Pacoti ainda permaneceria na classe 4. Para um estudo de enquadramento desse corpo hídrico, esse cenário se mostraria ineficaz para a recuperação dessa bacia hidrográfica, não proporcionando melhora significativa na qualidade de água para seu uso preponderante. Nesse caso o gestor público teria de tomar a decisão de efetuar um programa de redução bem mais arrojado.
No segundo cenário o foco foi apenas na melhoria da eficiência da capacidade de remoção das ETEs em 85\%, sem qualquer intervenção nas outras atividades agropecuárias. Nesse caso a concentração de fósforo na última seção de controle passaria a ser de $0,30 \mathrm{mg} \cdot \mathrm{L}^{-1}$, ou seja, praticamente o mesmo valor alcançado pelo primeiro cenário, em que se prevê maiores investimentos e implementação de efetivas políticas públicas. Percebe-se que apenas com a modificação das ETEs já é possível proporcionar uma redução na entrada da carga de fósforo no Açude Acarape do Meio em quase 50\%. O tempo para implementar essa estratégia seria relativamente pequeno. Verificou-se também que se outros programas voltados para a redução da carga de fósforo fossem implementados simultaneamente, possivelmente o processo de enquadramento seria exitoso.

\section{CONCLUSÕES}

Dispondo de uma densa rede de monitoramento de qualidade de água, distribuída em oito seções de rios e no Reservatório Acarape do Meio, foi possível constatar o severo estado de degradação naquela bacia provocado, sobretudo, pelas ETEs deficitárias, pela falta de saneamento básico na zona rural e por atividades agropecuárias danosas, principalmente a pecuária.

O diagnóstico da Bacia Hidrográfica do Açude Acarape do Meio a partir do levantamento dos seus usos e de sua ocupação do solo vieram a corroborar o modelo QUAL-UFMG, que mostrou uma bacia eminentemente rural sem qualquer saneamento básico; ETEs nas sedes municipais deficitárias, atuando muito mais como agentes poluidores do que como removedores de substâncias poluidoras. E também uma agricultura desassistida e com práticas de cultivo obsoletas, além de uma pecuária que gera provavelmente uma grande carga de dejetos sem qualquer controle ambiental.

Na simulação de cenários, foi possível inferir que apenas a recuperação das ETEs nas sedes municipais pode gerar efeitos positivos tão favoráveis quanto um grande e robusto programa de efetivação de metas, com altos investimentos orçamentários, para implementação de políticas voltadas para o equilíbrio das atividades em toda a Bacia Hidrográfica do Açude Acarape do Meio.

\section{REFERÊNCIAS}

AMIN, M.G.M; VEITH, T.L; COLLICK, A.S; KARSTEN, H.D.; BUDA, A.R. (2017) Simulating hydrological and nonpoint source pollution processes in a karst watershed. Agricultural Water Management. Disponível em: <http://www.sciencedirect.com/science/article/pii/ S0378377416302578>. Acesso em: 21 jul. 2016.
BRASIL. Resolução CONAMA no 430, de 13 de maio de 2011. Dispõe sobre as condições e padrões de lançamento de efluentes, complementa e altera a resolução n 357, de 17 de março de 2005, do Conselho Nacional do Meio Ambiente - CONAMA. Publicação do Diário Oficial da União, n. 92, p. 89. 2011. 
BRASIL. Resolução CONAMA nO 357, de 17 de março de 2005. Dispõe sobre a classificação de águas doces, salobras e salinas do território nacional. Publicação do Diário Oficial da União, n 53, p. 58-63. 2005.

CEARÁ, Assembleia Legislativa. Plano Estratégico dos Recursos Hídricos do Ceará. Pacto das Águas. Fortaleza. 408 p. INESP, 2008.

COMPANHIA DE GESTÃO DOS RECURSOS HÍDRICOS (COGERH). (2010) Plano de Gerenciamento das Águas das Bacias Metropolitanas. Fortaleza: COGERH.

Portal Hidrológico. Disponível em: <http://www.cogerh.com. br/portalhidrologico>. Acesso em: 15 jul. 2016.

COSTA, D.J.L.; TEIXEIRA, D. (2010) Aplicação de modelo de autodepuração para avaliação da qualidade da água Ribeirão do Ouro, Araraquara-SP. Revista UNIARA, v. 13, n. 1.

IBGE - Instituto Brasileiro de Geografia e Estatística. Censo Agropecuário 2014, Rio de Janeiro. Disponível em: <http://www. sidra.ibge.gov.br/dba/tabela>. Acesso em: 05 de maio de 2016.

LINDENSCHMIDT, K.E. (2006) Effect of complexity on parameter sensitivity and model uncertain in river water quality modeling. Ecological Modeling, v. 190, p. 72-86

MAILLARD, P.; SANTOS, N.A.P. (2008) A spatial-statistical approach for modeling the effect of non-point source pollution on different water quality parameters in the Velhas river watershed. Journal of Environmental Management, v. 86, n. 1, p. 158-170.

MENDES, W.J. da S. (2014) Adaptação do modelo de StreeterPhelps para modelagem da qualidade da água em uma grande bacia semiárida. Dissertação (Mestrado) - Universidade Federal do Ceará, Fortaleza.

MORIASI, D.; ARNOLD, J.G.; LIEW, M.W.V.; BINGNER, R.L.; HARMEL, R.D.; VEITH, T. (2007) Model evaluation guidelines for systematic quantification of accuracy in watershed simulations. Transactions of the ASABAE, v. 50, p. 885-900.
OLIVEIRA FILHO, A.A. de. (2014) Modelagem da qualidade da água do Rio Poti. Dissertação (Mestrado) - Universidade Federal do Ceará, Fortaleza.

PACHECO, C.H.A. (2009) Dinâmica espacial e temporal de variáveis limnológicas e sua influência sobre as cianobactérias em um reservatório eutrofizado: açude Acarape do Meio - CE. Dissertação (Mestrado) - Universidade Federal de Campina Grande, Paraíba.

PAZ, D.H.I. da; BARBOSA, I.M.B.R. (2010) Estudo da redução da carga orgânica lançada em um trecho do Rio Capibaribe para atendimento à legislação ambiental. In: SIMPÓSIO BRASILEIRO DE RECURSOS HÍDRICOS, 19., 2010. Anais... Maceió.

SALLA, R.M.; PEREIRA, C.E.; ALAMY FILHO, J.E.; PAULA, L.M. de; PINHEIRO, A.M. (2013) Estudo da autodepuração do Rio Jordão, localizado na bacia hidrográfica do Rio Dourados. Revista de Engenharia Sanitária Ambiental, v. 18, n. 2, p. 105-114.

SANTOS, V. da S.; FIRMINO, M.B.M.; VIEIRA, A.S.; CURI, W.F.; CURI R.C. (2006) Análise da vazão de diluição de poluentes em sistemas de otimização integrado de dois reservatórios em série no semiárido nordestino. In: SEMINÁRIO IBEROAMERICANO SOBRE SISTEMAS DE ABASTECIMENTO URBANO DE ÁGUA, 6. 2006. Anais... João Pessoa.

TEODORO, A.; IDE, C.N.; RIBEIRO, M.L.; BROCH, S.A.O.; SILVA, J.B. da. (2013) Implementação do conceito capacidade de diluição de efluentes no modelo de qualidade da água QUAL-UFMG estudo de caso no Rio Taquarazinho (MS). Revista Engenharia de Saneamento Ambiental, v. 18, n. 3.

VON SPERLING, M. (2003) Introdução a qualidade das águas e ao tratamento de esgotos. 5. ed. Belo Horizonte: Departamento de Engenharia Hidráulica e Ambiental, UFMG. 243 p.

(2007) Estudos e modelagem da qualidade da água de rios

2. ed. Belo Horizonte: Departamento de Engenharia Hidráulica e Ambiental, UFMG. 588 p. 